\title{
The Role of the Material of Active Screen During the Plasma Nitriding Process
}

\author{
Dorina KOVÁCS, ${ }^{1}$ Annamária SZABÓ, ${ }^{2}$ Alexandra KEMÉNY ${ }^{3}$ \\ Budapest University of Technology and Economics, Faculty of Mechanical Engineering, Department of \\ Materials Science and Engineering, Budapest, Hungary \\ ${ }^{1}$ dorina@eik.bme.hu \\ 2 annamaria.szabo97@gmail.com \\ 3alexa@eik.bme.hu
}

\begin{abstract}
In this research the effect of the active screen's material was investigated. 42CrMo4 steel was plasma nitrided with unalloyed steel, titanium and nickel active screen at 490 and $510{ }^{\circ} \mathrm{C}$ for $4 \mathrm{~h}$ in $75 \% \mathrm{~N}_{2}+25 \% \mathrm{H}_{2}$ gas mixture. Scanning electron microscopy (SEM), energy dispersive spectrometry (EDS) and X-ray photoelectron spectroscopy (XPS) were used for the characterisation of the surface properties. Iron-nitride was not formed on the surface with nickel screen. The evaluation of examination results showed that most of the detected nitrogen was molecular $\left(\mathrm{N}_{2}\right)$ in the formed layer.
\end{abstract}

Keywords: active screen plasma nitriding, X-ray photoelectron spectroscopy.

\section{Introduction}

The nitriding is a type of thermochemical surface treatment in which a hard, wear resistant surface layer can be formed by diffusing nitrogen into the surface which forms nitride with the atoms of the material. Nitrogen, as an interstitial alloy, dissolves in solid solutions of iron and can react and form compounds with certain alloys and constituents of steel [1, 2]. The vibratory motion is increased with the increasing of the nitriding temperature, which allows the diffusion of the nitrogen atoms into the lattice of iron. After the saturation of the solid solution, the nitrogen can create a compound with the iron atoms, which forms a continuous layer with higher hardness than the dissolved nitrogen in the solid solution $[3,4]$.

The plasma nitriding, also called ion-nitriding, was introduced in the 1920 s as a surface treatment. As soon as the gas ionization begins, the ions start to bombard the surface, which also called vaporization, because the precipitation of ions from the metal surface can rip off the atoms and contaminations. After the bombarding, which also serves the cleaning of the surface, the acce- lerated nitrogen ions heat the workpiece to the nitriding temperature with the controlling of the voltage, then the diffusion of nitrogens into the material and formation of nitrides starts [5-8]. [5-8]. Three different types of plasma nitriding exist: DCPN - direct current plasma nitriding, ASPN -active screen plasma nitriding and ASBPN - active screen biased plasma nitriding. The ASPN was developed to avoid the shortcomings (hollow cathode effect, corner effect) of the other method [9-11].

In ASPN treatment, the plasma is not created on the workpiece, but on a screen (often called as a cage) placed around the workpiece. As a result, at first, the active screen is bombarded by the ionized atoms and their associated positively charged ions. The sputtered iron-ions connect to the nitrogen-ions in the plasma through the screen. From these nitride particles, some of them can be deposited on the surface of the screen, but others due to the surface structure of the screen pass through and adsorb on the sample which is heated by the radiation and the gas inlet and continuous plasma flow maintained by the vacuum pump [11-13]. 
The active screen is characterized by the surface structure, the distance from the sample and the material, but in this paper, we will present only the effect of the material. Naeem [14] used austenitic stainless steel screen in his research. It was stated from the chemical composition analysis that nickel and chromium were found on the treated sample, which was caused by the deposition of the bombarded active screen. Yazdani et al. [15] nitride aluminium samples with unalloyed steel screen at $550{ }^{\circ} \mathrm{C}$, with $75 \% \mathrm{~N}_{2}+25 \% \mathrm{H}_{2}$ gas mixture for different time lenghts. $\mathrm{Fe}_{3} \mathrm{~N}$ layer was created on the samples which was formed from the sputtered iron of the screen combined with nitrogen.

Researchers not only pay attention to the plasma nitriding of metals but also for polymers. Polypropylene was nitrided between 5-15 mins to investigate how the process changes the adhesion properties of the surface. It can be observed that after this little time, Fe could deposit on the surface, which came from the active screen [16].

In this study tempered steel was nitrided by unalloyed steel, titanium and nickel coated active screen to investigate how the screen material affects the formation of the nitride layer and what bond can be made with the material of the sample.

\section{Experimental details}

\subsection{Materials}

42CrMo4 and Ti-6Al-4V ELI was used as a material which were cut into disks with a $20 \mathrm{~mm}$ diameter. The thickness of the samples was $6 \mathrm{~mm}$. The tempered steel was put into the furnace in tempered condition. All samples were ground on P80 to P2500 SiC particle size papers and then polished by a $3 \mu \mathrm{m}$ diamond suspension. Before the nitriding, it was degreased in an ultrasonic vibrated ethanol bath.

The materials and dimensions of the active screen are seen in Table 1. The samples were placed in the centre of the screen. The screens

Table 1. Materials and dimensions of the active screen

\begin{tabular}{|c|c|c|}
\hline Material & $\begin{array}{c}\text { Diameter } \\
\text { (mm) }\end{array}$ & $\begin{array}{c}\text { Hole size } \\
\text { (mm) }\end{array}$ \\
\hline DC01 & 100 & 5 \\
\hline $\mathrm{Ti} 1$ & 100 & 18 \\
\hline $\mathrm{Ti} 2$ & 55 & 6 \\
\hline $\mathrm{Ni}$ & 100 & 5 \\
\hline
\end{tabular}

were made by laser cutting. The nickel coating was electroplated in $\sim 70 \mu \mathrm{m}$ thickness.

\subsection{Nitriding parameters}

The plasma nitriding treatment was made in self-designed plasma nitriding equipment. The samples were nitrided at $490{ }^{\circ} \mathrm{C}$ with unalloyed steel and titanium screen, for 4 hours with $75 \% \mathrm{~N}_{2}+25 \% \mathrm{H}_{2}$ gas mixture. The nickel coated sample was nitrided for 4 hours at $510^{\circ} \mathrm{C}$ with the same gas mixture

\subsection{Characterization methods}

Stereomicroscopic (Olympus SZX16) images were taken from the upper surfaces of the nitrided samples. The microhardness of the layer was measured by a microhardness tester (Buehler IndentaMet 1105). For the EDS measurement Zeiss EVO MA10 electron microscope with EDAX Z2 detector, for the XPS Phoibos 100 MCD-5 detector were used.

\section{Plasma nitriding}

The first experiments were made on titanium to analyse the increase of the corrosion resistance, but it was observed that the sputtered particles from the screen were deposited on the surface. After this observation, the investigation of the effect of the screen material was started.

\subsection{Plasma nitriding of titanium with differ- ent active screens}

Before and after the nitriding, mass measurements were performed on the specimen, which results are shown in Table 2.

The mass increase was not observed after the nitriding with titanium screen, but it was increased with steel screen.

Figure 1 shows the surface after the nitriding.

As can be seen in Figure 1, the surface of the sample, which was nitrided with steel screen, was matt while the scratches of surface preparation were observed and the light was refracted differently by the optically active layer of the surface in the sample which was treated with titanium screen. It was clear that the golden yellow colour is a characteristic of TiN [17] was not formed

Table 2. Masses of titanium samples which were nitrided with different active screens

\begin{tabular}{|l|c|c|c|}
\hline \multicolumn{1}{|c|}{ Sample } & $\mathbf{m}_{\text {st. }} \mathbf{( g )}$ & $\mathbf{m}_{\text {end. }} \mathbf{( g )}$ & $\boldsymbol{\Delta} \mathbf{m}(\mathbf{g})$ \\
\hline Steel screen & 8.4130 & 8.4146 & 0.0016 \\
\hline Titanium screen & 8.3364 & 8.3365 & 0.0001 \\
\hline
\end{tabular}


which suggested that this type of nitride did not form on the surface.

The hardness of the titanium sample was

332 HV0.01 \pm 25 . With steel screen, the hardness was 661 HV0.01 \pm 32 which is two times higher than the base hardness, while the hardness was changed to $436 \pm 14 \mathrm{HV} 0.01$ after the nitriding with titanium screen. The titanium-nitrides can reach up to $1400 \mathrm{HV}$ hardness [18]. According to this, the compound layer was not formed, or it was so thin that the diamond head could pass over the entire layer.

Figure 2 shows the cross-section images of the samples.

It can be seen in the optical microscope images that the compound layer was not created on the surface. The microstructure of the samples was different near the edges and in the middle of the surface. Based on the hardness testing of the cross-section, the hardness was decreasing to the base hardness through $0.1 \mathrm{~mm}$, which proves with the previous observations that the nitrogen could diffuse into the material. Table 3 shows the the chemical composition of the surface measured with EDS.

It is seen that the titanium content of the surface was decreased compared to the base titanium content and iron appeared in a large amount with steel screen. On the samples, which treated with titanium screen, the titanium content was increased, but the content of the other elements was not changed significantly. Nitrogen appeared in both cases. These proved that the sputtered particles from the screen could deposit on the surface; moreover, it could cover the surface of the samples.

\subsection{Plasma nitriding of tempered steel with titanium active screen}

In the previous experiments, TiN was not created on the surface, but the sputtered particles from the surface deposited on the sample; therefore, $42 \mathrm{CrMo} 4$ was nitrided with a smaller screen. The sample was marked to ASPN Ti.

The results of the mass measurements are seen in Table 4.

The mass increase in this case, same as before, was significant, but the hardness was not increased. The hardness of the sample remained within the range of the deviation, $320 \pm 20$ HV0.01. The compound layer also did not form on the surface.

After the nitriding, different tones of colours were observed on the surface, which is seen in

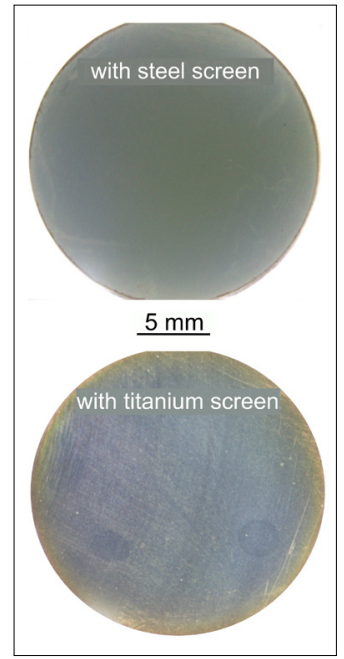

Figure 1. Stereomicroscopic images of titanium samples surface which was nitrided with different screens.

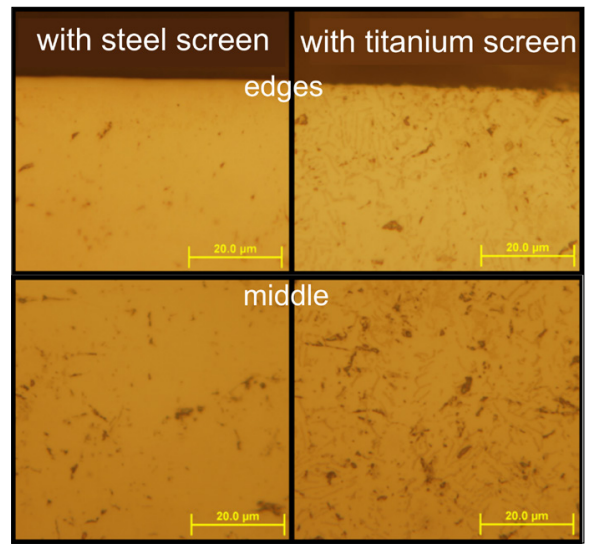

Figure 2. Optical microscopic images of crosssections of nitrided titanium samples which was nitrided with different screens.

Table 3. Chemical composition of the samples with EDS analysis which was nitrided with different screens

\begin{tabular}{|c|c|c|c|}
\hline $\begin{array}{c}\text { Element } \\
\text { (\%) }\end{array}$ & $\begin{array}{c}\text { Base } \\
\text { material }\end{array}$ & $\begin{array}{c}\text { With steel } \\
\text { screen }\end{array}$ & $\begin{array}{c}\text { With Ti } \\
\text { screen }\end{array}$ \\
\hline $\mathrm{Ti}$ & 83.18 & 11.19 & 85.21 \\
\hline $\mathrm{Al}$ & 6.10 & 0.18 & 6.72 \\
\hline $\mathrm{V}$ & 4.33 & 0.91 & 3.77 \\
\hline $\mathrm{O}$ & 6.15 & 7.34 & 1.14 \\
\hline $\mathrm{Si}$ & 0.24 & - & - \\
\hline $\mathrm{N}$ & - & 7.40 & 3.16 \\
\hline $\mathrm{Fe}$ & - & 72.98 & - \\
\hline
\end{tabular}


Table 4. Mass of the sample which was nitrided with titanium screen

\begin{tabular}{|c|c|c|c|}
\hline Sample & $\mathbf{m}_{\text {st. }}$ (g) & $\mathbf{m}_{\text {end }} \mathbf{( g )}$ & $\Delta \mathbf{m} \mathbf{( g )}$ \\
\hline ASPN_Ti & 12.5257 & 12.5267 & 0.0010 \\
\hline
\end{tabular}

Table 5. Chemical composition of the samples with EDS analysis which was nitrided with titanium screen

\begin{tabular}{|c|c|c|c|}
\hline $\begin{array}{c}\text { Component } \\
\text { (\%) }\end{array}$ & $\begin{array}{c}\text { Base ma- } \\
\text { terial }\end{array}$ & $\begin{array}{c}\text { ASPN_Ti } \\
\text { middle }\end{array}$ & $\begin{array}{c}\text { ASPN_Ti } \\
\text { edge }\end{array}$ \\
\hline $\mathrm{N}$ & - & 7.46 & 4.86 \\
\hline $\mathrm{O}$ & - & 5.17 & 3.51 \\
\hline $\mathrm{Al}$ & - & 0.17 & - \\
\hline $\mathrm{Si}$ & 0.28 & 0.24 & - \\
\hline $\mathrm{Ti}$ & - & 5.98 & 3.37 \\
\hline $\mathrm{Cr}$ & 1.41 & 1.18 & 1.21 \\
\hline $\mathrm{Fe}$ & 99.4 & 79.79 & 87.05 \\
\hline $\mathrm{Mo}$ & 0.12 & - & - \\
\hline $\mathrm{Mn}$ & 0.74 & - & - \\
\hline
\end{tabular}

Table 6. Chemical composition of the steel sample with XPS analysis which was nitrided with titanium screen

\begin{tabular}{|c|c|}
\hline Element & Amount (\%) \\
\hline C1s & 74.88 \\
\hline N1s & 2.22 \\
\hline O1s & 16.06 \\
\hline Ti2p & 4.24 \\
\hline Ca2p & 1.53 \\
\hline Mn2p & 0.36 \\
\hline Si2p & 0.38 \\
\hline Na1s & 0.07 \\
\hline
\end{tabular}

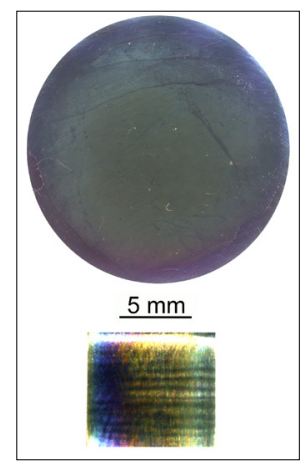

Figure 3. 42CrMo4 sample was nitrided with a titanium screen. The lower picture shows the formed colour transition during the nitriding.
Figure 3. Between these colours, the golden yellow appeared near the edges, and because of this EDS analysis was performed at different points. Table 5 shows the results of the measurements.

It can be observed that titanium was deposited from the surface to the sample, but the expected TiN was not formed near the edges because in this point the iron content was higher than in the middle; moreover, the nitrogen content was decreased too. XPS analysis was performed for a more accurate determination $[19,20]$ which results are seen in Table 6 .

The formed layer on the surface completely covers the base material, because iron, molybdenum and chromium were not seen in the spectrum. The formed layer contained titanium and nitrogen, but these elements were not bound. The different colours of the sample referred to the creation of titanium-oxide, but based on the measurements (however the formed bonds were closer to $\mathrm{TiO}_{2}$ than the TiN) it cannot be stated that the surface was covered only with a titanium-oxide layer. It is most likely that a $\operatorname{TiN}_{\mathrm{x}} \mathrm{O}_{\mathrm{y}}$ layer was formed on the surface; its thickness and composition was varied depending on the location.

\subsection{Plasma nitriding of tempered steel with nickel coated active screen}

The base material of the active screen was unalloyed steel, which was galvanized with nickel in $70 \mu \mathrm{m}$ thickness.

After the nitriding, the surface was given uniform grey colour (Figure 4.) in which the scratch of the polishing can be seen; it means that the compound layer also was not formed on the surface.

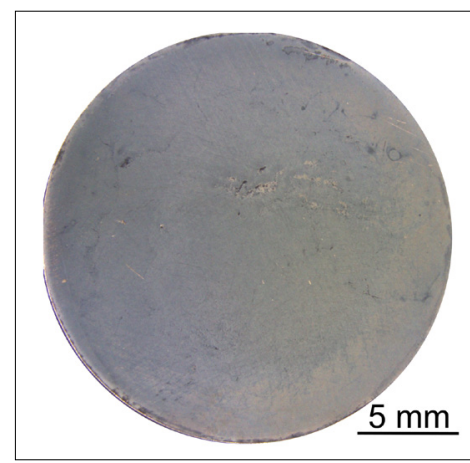

Figure 4. Stereomicroscopic image of 42CrMo4 sample which was nitrided with nickel coated active screen. 
It can be seen in the optical microscopic image (Figure 5.) that the compound layer was not created, which was proved by the hardness measurement. Again, the hardness was not increased in this sample; the values were within the deviation $420 \pm 45$ HV0,01.

Further analysis was performed by XPS for that the upper $100 \mathrm{~nm}$ layer was vaporized; then the chemical composition was measured in this depth. Figure 6 shows its results.

As it is seen in this figure, the nitrogen has not created a bond with the iron, so iron-nitride did not appear - which verifies the previous suppositions. Most of the detected nitrogen (84\%) was molecular $\left(\mathrm{N}_{2}\right)$ on the sputtered layer. In this depth, N-C were presented in a low amount (16\%), but it does not have a hardening effect to the surface.

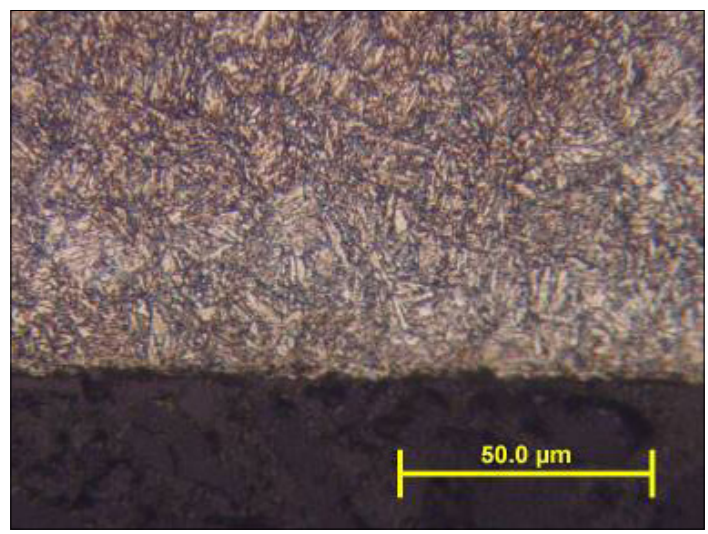

Figure 5. The microstructure of 42CrMo4 sample which was nitrided with nickel coated screen.

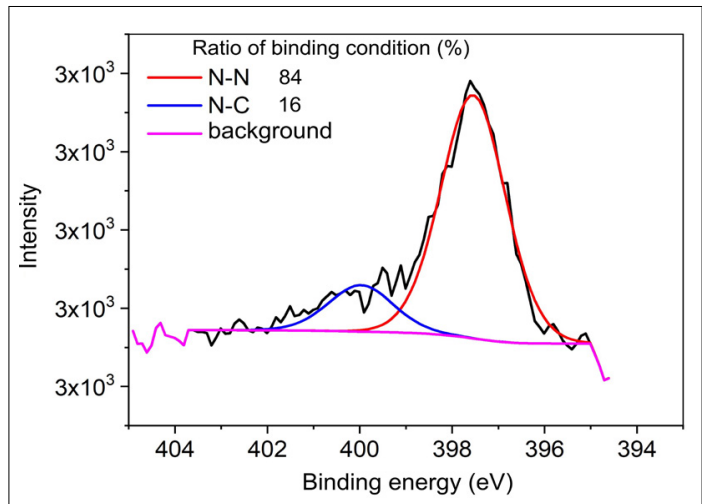

Figure 6. XPS characteristic diagram of $42 \mathrm{CrMo} 4$ sample which was nitrided with nickel coated screen.

\section{Conclusion}

The material of the active screen affects the surface properties of the nitrided sample during active screen plasma nitriding in the following ways:

- no hardening effect occurs;

- the compound layer does not form on the surface, so iron-nitride was not created;

- particles from the active screen were deposited on the sample.

With nickel coated active screen plasma nitriding at $510{ }^{\circ} \mathrm{C}$, for 4 hours with $75 \% \mathrm{~N}_{2}+25 \% \mathrm{H}_{2}$ gas mixture only nickel from the surface of the screen has adhered to the sample surface at hundreds of nm thickness, and iron nitride phases were not formed. This can even be considered as a new surface alloying process.

\section{Acknowledgement}

The authors are grateful to Viktor Takátcs from the Institute for Nuclear Research and to Gábor Dobos from the from BME, Department of Atomic Physics for the XPS measurements.

\section{References}

[1] Yaghmaee M.S, Kaptay G.: The Solubility of Nitrogen and Nitrides in Ternary Liquid Iron Alloys. The Limits of the 'Solubility Product' Concept. Materials Science Forum 414-415. (2003) 491496.

[2] Kolozsváry Z.: Nitriding structure and properties of nitrided layar. ASM Handbook, Volume 4D, Heat Treating of Irons and Steels (2014) 88-96. https://doi.org/10.31399/asm.hb.v04d.a0005986

[3] Szilágyiné B. A.: Trends of nitriding processes. Production Processes and Systems, 6. (2013) 57-69.

[4] Aizawa T., Wasa K.: Low temperature plasma nitriding of inner surfaces in stainless steel mini-/ micro-pipes and nozzles, Micromachines. 8. (2017) 1-9. https://doi.org/10.3390/mi8050157

[5] Szilágyiné B. A., Kocsisné B. M.: Comparison of gas and plasma nitrocarburised surface layer of 16 CrMo5 steel. Proceedings - European Conference on Heat Treatment and $21^{\text {st }}$ IFHTSE Congress (2014) 551-558.

[6] Börner K., Burlacov I., Spies H., Biermann H., Hamann S., Röpcke J.: Investigations on the active screen plasma nitriding process. In: $13^{\text {th }}$ International Conference on Plasma Surface Engineering (2012) 96-99.

[7] Middendorf C., Mader W.: Growth and microstructure of iron nitride layers and pore formation in $\varepsilon$ - $F e 3 N$. Zeitschrift für Metallkunde/Materials Research and Advanced Techniques 94. (2003) https://doi.org/10.3139/146.030333 
[8] Kenéz L., Kutasi N., Filep E., Jakab-Farkas L., Ferencz L.: Anodic plasma nitriding in hollow cathode (HCAPN). HTM - Journal of Heat Treatment and Materials, 73. (2018) 96-105. https://doi.org/10.3139/105.110344.

[9] Li Y., Zhang S., He Y., Zhang L., wang L.: Characteristics of the nitrided layer formed on AISI 304 austenitic stainless steel by high temperature nitriding assisted hollow cathode discharge. Materials and Design, 64. (2014) 527-534.

https://doi.org/10.1016/j.matdes.2014.08.023.

[10] Sousa de R. R. M., Araújo de F. O., Costa da J. A. P., Dumelow T., Oliveira de R. S., Alves C.: Nitriding in cathodic cage of stainless steel AISI 316: Influence of sample position. Vacuum 83. (2009) 1402-1405.

https://doi.org/10.1016/j.vacuum.2009.04.054

[11] Salavat M. K., Soltanieh M., Niasari M. H.: Diffusion Layer Growth Mechanism in ASPN Method Using an Iron Cage for St52 Steel. In: Proceedings of the $2^{\text {nd }}$ World Congress on Mechanical, Chemical, and Material Engineering (MCM'16) (2016) 1-8. https://doi.org/10.11159/mmme16.106

[12] Gallo C. S., Dong H.: On the fundamental mechanisms of active screen plasma nitriding. Vacuum, 84. (2009) 321-325. https://doi.org/10.1016/j.vacuum.2009.07.002

[13] Zaho C., Li C. X., Dong H., Bell T.: Study on the active screen plasma nitriding and its nitriding mechanism. Surface and Coatings Technology, 201. (2006) 2320-2325. https://doi.org/10.1016/j.surfcoat.2006.03.045

[14] Naeem M., Sha M., Zaka-ul-islam M., Ashiq A., Díaz-Gullién J. C., Shahzad M., Zakaullah M.: Enhanced surface properties of plain carbon steel using plasma nitriding with austenitic steel cathodic cage. Materials and Design, 108. (2016) 745-753. https://doi.org/10.1016/j.matdes.2016.07.044
[15] Yazdani A., Soltanieh M., Aghajani H.: Active screen plasma nitriding of Al using an iron cage: Characterization and evaluation. Vacuum, 122. (2015) 127-134.

https://doi.org/10.1016/j.vacuum.2015.09.018

[16] Kauling A. P., Soares G. V., Figueroa C. A., Oliverira de R. V. B., Baumvol I. J. R., Giacomelli C., Miotti L.: Polypropylene surface modification by active screen plasma nitriding. Materials Science and Engineering, C, 29. (2009) 363-366.

https://doi.org/10.1016/j.msec.2008.07.002

[17] Kamat A. M., Copley S. M., Todd J. A.: Effect of processing parameters on microstructure during laser-sustained plasma (LSP) nitriding of commercially-pure titanium. Acta Materiala, 107. (2016) 72-82.

https://doi.org/10.1016/j.actamat.2016.01.051

[18] Nishimoto A., Nii H., Narita, Akamatsu K.: Simultaneous duplex process of TiN coating and nitriding by active screen plasma nitriding. Surface and Coatings Technology, 228. (2013) 558-562. https://doi.org/10.1016/j.surfcoat.2012.04.021

[19] Kovách G., Csorbai H., Dobos G., Karacs A., Pető G.: Formation and characterization of electric contacts on CVD diamond films prepared by ion implantation, Materials Science Forum, 473-474. (2005) 123-128.

https://doi.org/10.4028/www.scientific.net/ MSF.473-474.123

[20] Takáts V., Csík A., Hakl J., Vad K.: Diffusion induced atomic islands on the surface of $\mathrm{Ni} / \mathrm{Cu} \mathrm{na}$ nolayers. Applied Surface Science, 440. (2018) 275-281. https://doi.org/10.1016/j.apsusc.2018.01.087 